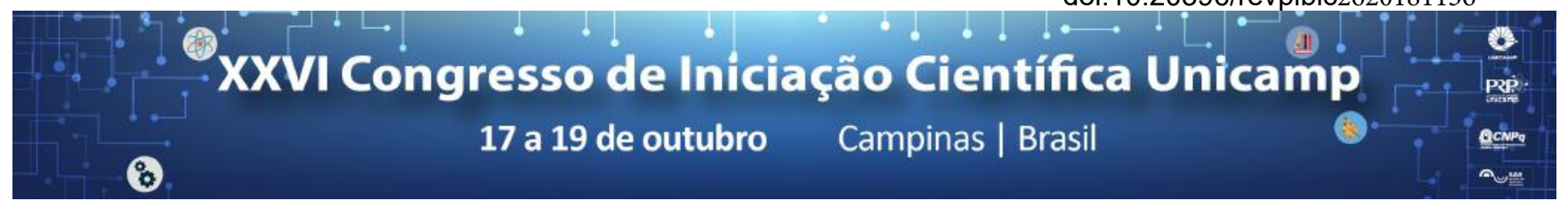

\title{
Projeto e Condicionamento de Sinais de Sensores Embarcados usados para o Transporte Inteligente de Alimentos na Cadeia do Frio.
}

\section{Pedro Henrique Estimo*, Leandro Tiago Manera, Alexandre da Luz Kume.}

\section{Resumo}

O projeto envolve a colaboração do Laboratório de Soluções em Eletrônica e Rádiofrequência (LSERF) o qual visa o desenvolvimento de um instrumento embarcado capaz de medir as grandezas principais na análise científica da complexa cadeia do frio de logística no Brasil, com o intuito de monitorar as condições dos produtos transportados. Através de um microcontrolador, módulos de sensores e a montagem de circuitos de condicionamento de sinais, o dispositivo desenvolvido é capaz de fornecer informações da temperatura, umidade relativa, luminosidade, pressão atmosférica e geoposicionamento, podendo ser analisadas para garantir a certificação de segurança, evitar perdas da qualidade e o desperdício do produto.

\section{Palavras-chave:}

Sensores Embarcados, Cadeia do Frio, Instrumentação.

\section{Introdução}

Há muito desperdício de mercadorias sensíveis devido a condições adversas durante $o$ seu transporte $e$ armazenamento, como a temperatura e umidade inadequadas. O objetivo principal deste trabalho é o projeto de um dispositivo de aplicação científica no estudo e monitoramento de temperatura, aceleração (vibração), umidade relativa, luminosidade $e$ o geoposicionamento através do sistema de posicionamento global (GPS) para o uso na chamada cadeia do frio. O projeto de instrumentos embarcados de multivariáveis físicas auxilia na pesquisa científica fornecendo dados mais precisos sobre a condições reais a qual o produto monitorado está submetido, permitindo uma melhoria na qualidade e a certificação ao cumprimento de normas.

\section{Resultados e Discussão}

Utilizou-se os sensores de saída analógica fototransistor para a medição da luminosidade e o termoresistor PT100 para a medição da temperatura. Já os sensores de saída digital utilizados foram o sensor BMP180 para a medição de pressão atmosférica, o sensor DHT22 para a medição de temperatura e umidade e o sensor LM75 apenas para a medição da temperatura. Por fim utilizou-se também o módulo GY-GPS6MV2 para a obtenção das coordenadas de geoposição.

Foi realizado o modelo elétrico de simulação no OrCAD dos circuitos e feito sua montagem em uma placa de circuito impresso podendo ser visualizados na Figura 1 abaixo.

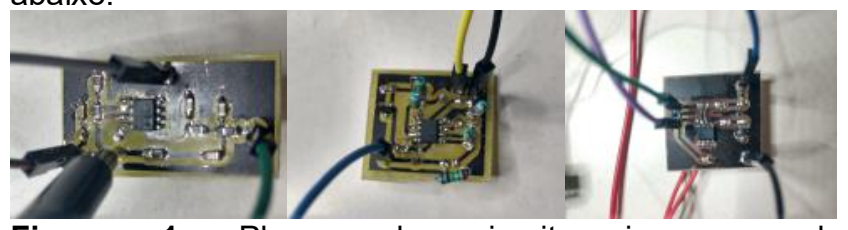

Figura 1. Placas de circuito impresso de condicionamento de sinal com os componentes soldados.

A comunicação estabelecida entre o sensor BMP180, o LM75 e o display organic light-emititing diode (OLED) seguiu o protocolo Inter-Integrated Circuit (I2C). RealizouRealizou-se a programação do microcontrolador STM32f103 com arquitetura ARM M3 para efetuar o condicionamento de sinais provindos dos módulos sensores, bem como para a exibição dos mesmos via terminal e via display OLED, conforme mostrado nas Figuras 2 e 3, respectivamente. Para garantir maior confiabilidade dos dados da temperatura, isto é, reduzir os erros de drifit e de resposta não-linear, projetou-se um circuito de condicionamento composto por fonte de corrente, filtro e amplificador de ganho.

Ao compararmos os resultados dos sensores de temperatura LM75, DHT22 e o PT100, verificou-se que o dispositivo PT100 obteve maior precisão e acurácia. Como resultado foi possível observar que o sistema responde bem à mudanças das grandezas físicas analisadas, obtendo resultados confiáveis e precisos.

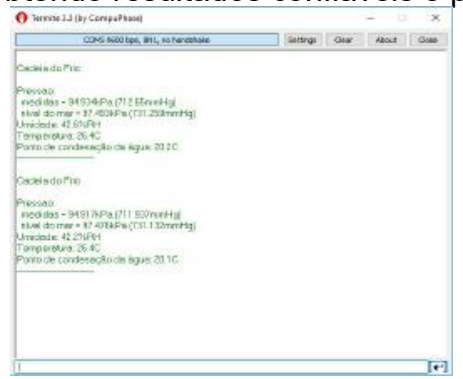

Figura 2. Visualização das medidas das grandezas físicas enviadas pela serial ao terminal.

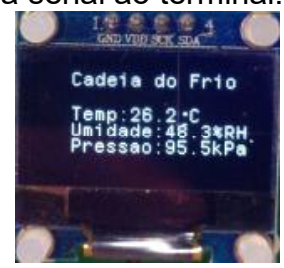

Figura 3. Visualização das medidas das grandezas no display OLED.

\section{Conclusões}

O trabalho envolveu técnicas de projeto (layout), construção e aplicação de um sistema embarcado. O sistema é capaz de realizar as leituras das diversas grandezas e armazená-las em variáveis que posteriormente podem ser monitoradas tanto por usuários quanto por softwares de gestão de processos, almejando a diminuição de desperdício e aumento da produtividade. 